Background Low-dose mercury exposure has been shown to be associated with adverse childhood health outcomes. Fish is the major source of mercury exposure in children. Our aim was to investigate the associations between estimated fish intake with total mercury (tHg), inorganic mercury $(\mathrm{iHg})$, and methylmercury $(\mathrm{MeHg})$.

Methods Based on fish food frequency questionnaire (FFQ) data, subjects above the top and below the bottom quartiles of monthly fish intake frequency were contacted for recruitment. Subject hair tHg, $\mathrm{iHg}, \mathrm{MeHg}$ levels were determined, and fish intake assessed by fish FFQ and 14-day food diary (FD). Associations between fish intake and hair mercury were analysed.

Results 96 children were recruited and 38 of them completed the FD. Among these 96 children and those who have FD data, $55 \%$ and $50 \%$ were high fish consumers, respectively. The mean ratio of $\mathrm{iHg}: \mathrm{MeHg}$ was 1:1.4. Comparisons between hair mercury levels and fish intake levels of high and low fish consumers are shown in Figure 1. Fish intakes calculated from both FFQs and FD were positively correlated with $\mathrm{tHg}$, iHg and $\mathrm{MeHg}$ (all $\mathrm{p}<0.05)$. However, in general, better correlations were found between FD data and hair mercury (Spearman's rho for tHg = 0.416; $\mathrm{iHg}=0.352 ; \mathrm{MeHg}=0.448)$ than between FFQ and hair mercury (Spearman's rho for $\mathrm{tHg}=0.308$; $\mathrm{iHg}=0.360$; $\mathrm{MeHg}=0.262$ ).

Conclusions Fish intake data obtained from both FFQs and FDs were positively associated with hair mercury levels. FDs performed better than FFQs. The high proportion of $\mathrm{iHg}$ : $\mathrm{MeHg}$ is unexpected and warrants further study.

\section{PS-002 EFFECTS OF E-WASTE EXPOSURE ON THE SYNTHESIS OF HAEMOGLOBIN IN PRESCHOOL CHILDREN}

${ }^{1} \mathrm{~L} \mathrm{Ma},{ }^{2} \mathrm{TY}$ Wang, ${ }^{3}{ }^{\mathrm{Y} B}$ Chen. ${ }^{1}$ Pediatrics, The Second Affiliated Hospital of Shantou University Medical College, Shantou, China; ${ }^{2}$ Pediatrics, Capital Institute of Pediatrics, Beijing, China; ${ }^{3}$ Pediatrics, Guangdong Maternity and Child Health Care Hospital, Guangzhou, China

\subsection{6/archdischild-2014-307384.297}

Objective Guiyu is the major electronic-waste (e-waste) recycling town in China. This study was to measure the effect of e-waste exposure on the synthesis of haemoglobin $(\mathrm{Hb})$ in preschool children.

Methods 222 children lived at Guiyu town and 204 children lived in a no e-waste polluted town were chosen to test their blood lead, $\mathrm{Hb}$, ferritin, folate, vitamin $\mathrm{B}_{12}$ levels and hemoglobinopathy, then fill the self-questionnaires by their parents.

Results There were no significant differences in the levels of ferritin, folate, vitamin $\mathrm{B}_{12}$ between exposure and control groups, and all children had been excluded thalassemia. The blood lead levels (BLLs) and rate of BLLs $\geq 10 \mathrm{ug} / \mathrm{dL}$ in exposure group were signifcantly higher than that in control group (all p < 0.01). Three groups were divided according to BLLs (Group A: $<5.0 \mathrm{ug} / \mathrm{dL}$, Group B: 5.0-9.9 ug/dL, Group C: $\geq 10.0 \mathrm{ug} / \mathrm{dL})$. It can be seen that the levels of $\mathrm{Hb}$ were decreased along with elevated BLLs significantly in exposure group $(\mathrm{F}=3.52, \mathrm{p}=$ $0.03)$, however, not shown in control group $(\mathrm{F}=1.98, \mathrm{p}=$ 0.14). Furthermore, the prevalence rate of anaemia along with BLLs $\geq 10 \mathrm{ug} / \mathrm{dL}$ in exposure group was significant higher than that in control group $(4.0 \%$ vs. $0.5 \%, \mathrm{p}<0.05)$, and the prevalence rate of anaemia without BLLs $\geq 10 \mathrm{ug} / \mathrm{dL}$ and iron deficiency in exposure group was significant higher than that in control group $(6.5 \%$ vs. $2.0 \%, \mathrm{p}<0.05)$.
Conclusion Different from the general environment, the lead exposure in e-waste area might aggravate the inhibition of synthesis of $\mathrm{Hb}$, and other potential e-waste toxicants might also have a responsibility for it.

\section{PS-003 ACCEPTABILITY AND INITIAL EFFICACY OF SIMPLE, WRITTEN, EDUCATIONAL MATERIALS FOR ADOLESCENT MOTHERS IN THE UNITED STATES}

${ }^{1} \mathrm{D}$ Davis, ${ }^{2} \mathrm{MC}$ Logsdon, ${ }^{3} \mathrm{R}$ Stikes, ${ }^{4} \mathrm{R}$ Ratterman, ${ }^{1} \mathrm{~L}$ Ryan, ${ }^{1} \mathrm{~J}$ Meyers. ${ }^{1}$ Pediatrics, University of Louisville, Louisville, USA; ${ }^{2}$ School of Nursing, University of Louisville, Louisville, USA; ${ }^{3}$ Nursing, University of Louisville Hospital, Louisville, USA; ${ }^{4}$ Teenage Parent Program, Jefferson County Public Schools, Louisville, USA

\subsection{6/archdischild-2014-307384.298}

Background Health literacy has been associated with a variety of health outcomes and behaviours in adults and children. Relatively little is known about health literacy of pregnant and parenting teens. The current study evaluated the acceptability and efficacy of simple, written, educational materials.

Methods A convenience sample $(\mathrm{n}=129)$ of English-speaking adolescent mothers $(\mathrm{M}=16.98$ years; $\mathrm{SD}=1.04)$ was recruited from a public school system. A simple pamphlet was developed for each of 4 common topics (breastfeeding, postpartum depression, infant care, and bonding). Participants completed a pretest on knowledge, read a simple educational pamphlet, and completed an immediate posttest. Participants also completed the Parental Health Literacy Activities Test (PHLAT) and a measure of acceptability. A two-week posttest followed. The CochranArmitage test of trends and repeated measures ANOVA were used.

Results The teens agreed $(\mathrm{n}=96 ; 82.1 \%$ ) or partially agreed ( $\mathrm{n}$ $=14 ; 12 \%)$ that the pamphlets were easy to read. Knowledge improved on 6 of the 10 questions. Correct responses to the PHLAT items ranged from 27.6\%-97.6\% $(\mathrm{M}=61.79 \%$ $\pm 16.7 \%)$. The intervention was associated with an increase in PPD (67.4\% vs. $76.4 \%$ vs. $84.3 \%, \mathrm{p}=0.031)$, baby bonding $(74.8 \%$ vs. $87.8 \%$ vs. $86.2 \%, p=0.013)$ and breastfeeding (58.5\% vs. $75.6 \%$ vs. $79.7 \%, \mathrm{p}=0.005)$ knowledge over time, but had no effect on infant care knowledge over time $(94.3 \%$ vs. 97.6\% vs. $95.9 \%, \mathrm{p}=0.434)$.

Conclusions/discussion Simple, written pamphlets, following US national health literacy guidelines, improved knowledge over time and were acceptable to adolescent mothers. Health literacy skills were limited and appear to be associated with initial knowledge.

\section{PS-004 ASSOCIATION OF THE 45T > G ADIPONECTIN GENE POLYMORPHISM WITH METABOLIC SYNDROME IN EGYPTIAN FEMALE ADOLESCENTS}

${ }^{1} \mathrm{M}$ Zaki, ${ }^{2} \mathrm{M}$ Abd EL-Salam, ${ }^{1} \mathrm{~N}$ Hassan, ${ }^{3} \mathrm{~S}$ Ismail, ${ }^{1} \mathrm{~S}$ Kamal, ${ }^{2} \mathrm{M}$ Zzaher, ${ }^{3} \mathrm{~A}$ Elkhouly. ${ }^{1}$ Biological Anthropology, National Research Centre, Cairo, Egypt; ${ }^{2}$ Pediatric and Department, Faculty of Medicine, Cairo, Egypt; ${ }^{3}$ Medical Molecular Genetics, National Research Centre, Cairo, Egypt

\subsection{6/archdischild-2014-307384.299}

Background Adiponectin gene (ADIPOQ) single nucleotide polymorphisms (SNPs) have been shown to influence adiponectin levels and have been associated with risk for obesity and insulin resistance (IR). However, these associations have not been fully examined in Egyptian adolescents. The aim of this study was to 